\title{
Utilization of research knowledge in sustainable development pathways: \\ Insights from a transdisciplinary research-for-development programme
}

\author{
J. Jacobi ${ }^{1,2)}$, A. Llanque ${ }^{3)}$, S. Bieri ${ }^{1)}$, E. Birachi' ${ }^{4)}$, R. Cochard ${ }^{5)}$, N. Depetris Chauvin ${ }^{6}$, C. Diebold ${ }^{1)}$, R. \\ Eschen $^{7)}$, E. Frossard ${ }^{8)}$; T. Guillaume ${ }^{9)}$, S. Jaquet ${ }^{1)}$, F. Kämpfen ${ }^{10)}$, M. Kenis ${ }^{7)}$, D. I. Kiba ${ }^{8)}$, H. Komarudin ${ }^{11)}$, \\ J. Madrazo ${ }^{12)}$, G. Manoli ${ }^{13)}$, S. M. Mukhovi ${ }^{14)}$, V. T. H. Nguyen ${ }^{15)}$, C. Pomalègni ${ }^{16)}$, S. Rüegger ${ }^{17)}$, F. \\ Schneider ${ }^{1)}$, N. TriDung ${ }^{18)}$, P. von Groote ${ }^{19)}$, M. Winkler ${ }^{20,21)}$, J. G. Zähringer ${ }^{1)}$, Robledo-Abad, C. ${ }^{22)}$
}

1) Centre for Development and Environment, University of Bern, Switzerland

2) Institute of Geography, University of Bern, Switzerland

3) University of San Simón, Cochabamba, Bolivia

4) International Center for Tropical Agriculture (CIAT), Rwanda

5) Institute of Geography and Sustainability, University of Lausanne, Switzerland

6) HES-SO, Haute Ecole de Gestion de Genève, Switzerland

7) CABI, Switzerland

8) Group of Plant Nutrition, Institute of Agricultural Sciences, ETH Zurich, Switzerland

9) Laboratory of Ecological Systems, Ecole Polytechnique Fédérale de Lausanne, and Swiss Federal Institute for Forest, Snow and Landscape Research, Switzerland

10) University of Lausanne, Switzerland

11) Center for International Forestry Research (CIFOR), Indonesia

12) Geographic Information Systems Laboratory, EPFL, Switzerland

13) Department of Civil, Environmental, and Geomatic Engineering, Institute of Environmental Engineering, ETH Zurich, Switzerland

14) Department of Geography and Environmental Studies, University of Nairobi, Kenya

15) Consultative and Research Center on Natural Resource Management (CORENARM), and Institut de Géographie et Durabilité (IGD), University of Lausanne

16) National Agricultural Research Institute of Benin (INRAB), Benin

17) Department of Humanities, Social and Political Science, ETH Zurich, Switzerland

18) Alberta Innovates \& Adjunct Faculty-Civil \& Environmental Engineering at University of Alberta, Canada

19) Institute of Social and Preventive Medicine (ISPM), University of Bern, Switzerland

20) Department of Epidemiology and Public Health, Swiss Tropical and Public Health Institute, Basel, Switzerland

21) University of Basel, Switzerland

22) Transdisciplinarity Laboratory (D-USYS TdLab), Institute for Environmental Decisions, ETH Zurich, Zurich, Switzerland

Corresponding Author: Carmenza Robledo-Abad, carmenza.robledo@usys.ethz.ch

Keywords: Transdisciplinarity; knowledge co-creation; knowledge utilization; research for development

Jacobi, J., Llanque, A., Bieri, S., Birachi, E., Cochard, R., Chauvin, N. D., ...

Robledo-Abad, C. (2020). Utilization of research knowledge in sustainable development

pathways: insights from a transdisciplinary research-for-development programme.

Environmental Science and Policy, 103, 21-29. https://doi.org/10.1016/

j.envsci.2019.10.003 


\begin{abstract}
This study contributes to the ongoing discussion on how to attribute and evaluate the contribution of transdisciplinary research to sustainable development. As co-created knowledge is a key product of transdisciplinary research, we tested the hypothesis that the extent to which this knowledge is utilized beyond the projects consortia, in different areas - from scientific methods and insights to policy decisions - and across a continuum of geographical scales can be used to identify potential impact pathways. With this aim we developed an analytical framework that links the transdisciplinary process to six possible utilization stages as indicators for usability of co-created knowledge and implemented it using a survey and semi-structured interviews in 22 research projects active in 36 countries. Our results show that even during the implementation of the projects, co-created knowledge is utilized by multiple actors at different stages, in all areas and scales simultaneously, suggesting multiple impact pathways. Utilization of project knowledge was predominantly indicated for national-level policymaking and research partners named co-creation of knowledge with key stakeholders as the most frequently used mechanism for promoting knowledge utilization. Closer analysis showed different understandings of and approaches to knowledge co-creation. These can be linked to weaker or stronger definitions of transdisciplinarity. The analysis shows that when using strong transdisciplinarity approaches researchers need to face challenges in encompassing multiple epistemologies and in facilitating dialogue. Some results suggest that inclusion and collaboration by co-created knowledge can empower actors otherwise excluded. Our research shows that although transdisciplinary projects have non-linear impact pathways, these can be partially assessed using the proposed analytical framework. Further, our results indicate interesting links between usability - through knowledge utilization - inclusion and collaboration regarding knowledge co-creation in transdisciplinary research. We conclude with the observation that transdisciplinarity and its requirements still need to be better understood by actors within and beyond the research community.
\end{abstract}

\title{
1. Introduction
}

The effect of research projects on sustainable development pathways is a matter of ongoing debate in the context of development cooperation (Wiek et al., 2012; Brandt et al., 2013; Miller et al., 2014; Schneider and Buser, 2018). This is partly because, during the last decades, an increasing share of so-called official development assistance has been invested in research for development. Although the debate demonstrates agreement about the urgency of understanding the effectiveness of these investments, there are multiple - and often contradictory - views on how to define, attribute, and evaluate results and outcomes of research-fordevelopment projects (Spreckley, 2009; Belcher and Palenberg, 2018). In addition, there is a lack of contextualized studies about science-based mechanisms that facilitate positive sustainable development outcomes (Nutley et al., 2007; ESRC, 2011; Zähringer et al., 2019).

The role of science in achieving sustainable development has long become a concern for governments and public sectors, and the contribution of participatory research to transformative processes is the subject of ongoing debate (Archibald et al., 2016; Thornton et al., 2017). Transdisciplinary research is one of the answers that the scientific community provides for addressing this challenge. Transdisciplinary approaches aim at increasing the relevance, credibility, and legitimacy of scientific research by securing the active participation of non-academic actors in research (Russell et al., 2008; Bunders et al., 2010; Basche et al., 2014; Thompson 
et al., 2017; Hansson and Polk, 2018). But a clear attribution of the contribution or impact of transdisciplinary projects on development pathways is a serious challenge (Thompson et al., 2017; Belcher and Palenberg, 2018; Schneider and Buser, 2018; Matenga et al., 2019).

Aiming to contribute to this debate, we analysed the utilization of co-created knowledge by different stakeholders as a proxy for understanding the transformative capacity of co-created knowledge generated by 22 research projects implemented by transdisciplinary consortia in 35 countries in Africa, Asia, and Latin America. All projects included in the analysis are part of the Swiss Programme for Research on Global Issues for Development (r4d programme), a ten-year research programme that supports transboundary, partnershipbased inter- and transdisciplinary research with a focus on least developed, low- and middle-income countries. The projects in the r4d programme are grouped into six modules: Ecosystems, Food Security, Public Health, Employment, Social Conflict, and an Open Call module. The question at stake is thus if there is evidence showing how co-created knowledge is being utilized, in which areas, at what scales, and through which mechanisms.

\section{Methods: analytical framework, data collection and analysis}

\subsection{Analytical framework}

Transdisciplinary research is gaining recognition for contributing to solve current sustainability challenges (Levesque et al., 2019). For doing so, transdisciplinary research is problem-oriented and combines scientific cooperation between different disciplines (interdisciplinarity) with the participation of different types of actors in the creation or production of knowledge (Hirsch Hadorn et al., 2006; Wiek et al., 2012; Miller et al., 2014; Polk, 2015).

For the purpose of this analysis we understand societal impact as long-term social, cultural, environmental and economic returns or benefits from research results or products of publicly funded research that lead to sustainability transformation (Bornmann, 2013). Thus, societal impacts include and go beyond transformation within the project sphere and looks towards contribution to transformation in the sphere of socio-ecological systems (see Fig. 1). 


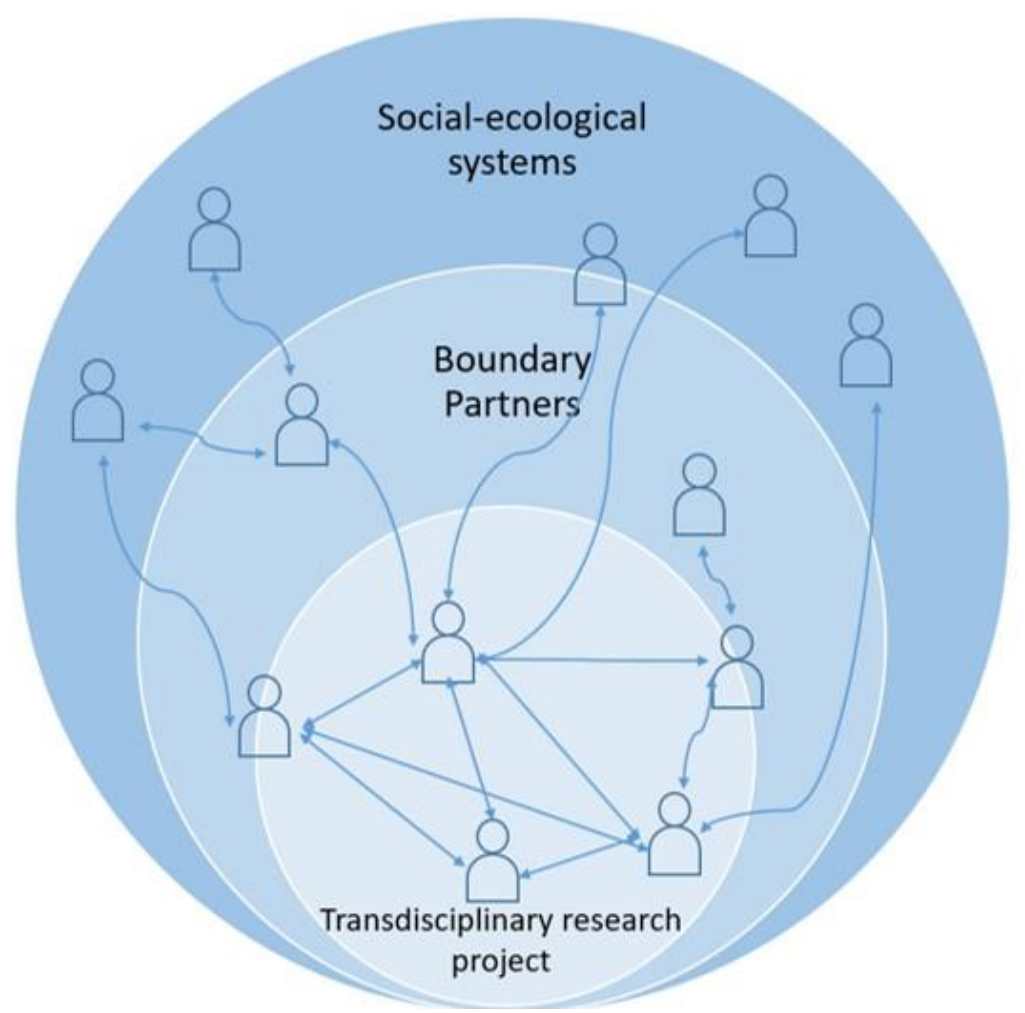

Fig. 1: From the transdisciplinary research projects spheres to impacts in other spheres (based on Schuetz et al., 2017). Actors in the sphere of transdisciplinary research projects include academic and non-academic actors.

Co-creation or co-production of knowledge is a key characteristic of transdisciplinary research and can be understood as a process in which the knowledge of different actors is brought together and which is designed to facilitate decision-making processes (Bunders et al., 2010). Polk (2015:111) describes transdisciplinary coproduction as "a research approach targeting real life problem solving. Knowledge is co-produced through the combination of scientific perspectives with other types of relevant perspectives and experience from real world practice including policy-making, administration, business and community life". Schneider et al. (2019) propose that transdisciplinarity is essentially a mode of knowledge production that can contribute to societal transformation. Due to often similar definitions of knowledge co-creation and knowledge co-production, we consider these two terms as interchangeable for the purpose of this article. Knowledge co-creation goes beyond the participation of non-academic actors in the research process merely as informants but as active stakeholders, and preferably from the very outset of the project, which includes the negotiation and agreement of research questions and activities. Consequently, in a transdisciplinary research project we understand "researchers" as all academic and non-academic actors who co-create knowledge. The earlier and more empowered the non-academic participation is in the process of co-creating knowledge, the stronger the indication for transdisciplinarity, whereas mere consultation of different stakeholders according to the conditions set by academic actors indicates weaker understandings of transdisciplinarity (see Krütli et al. 2010; Jahn et al. 2012).

Transdisciplinary approaches are often guided by a normative understanding of research (Pohl et al., 2017). Jahn et al. (2012) propose an ideal transdisciplinary process that combines societal views and values with 
scientific problems, discourse and practice. The process includes three main phases: the formation of a common research object, production of knew knowledge, and transdisciplinary integration (Fig. 2, left side).

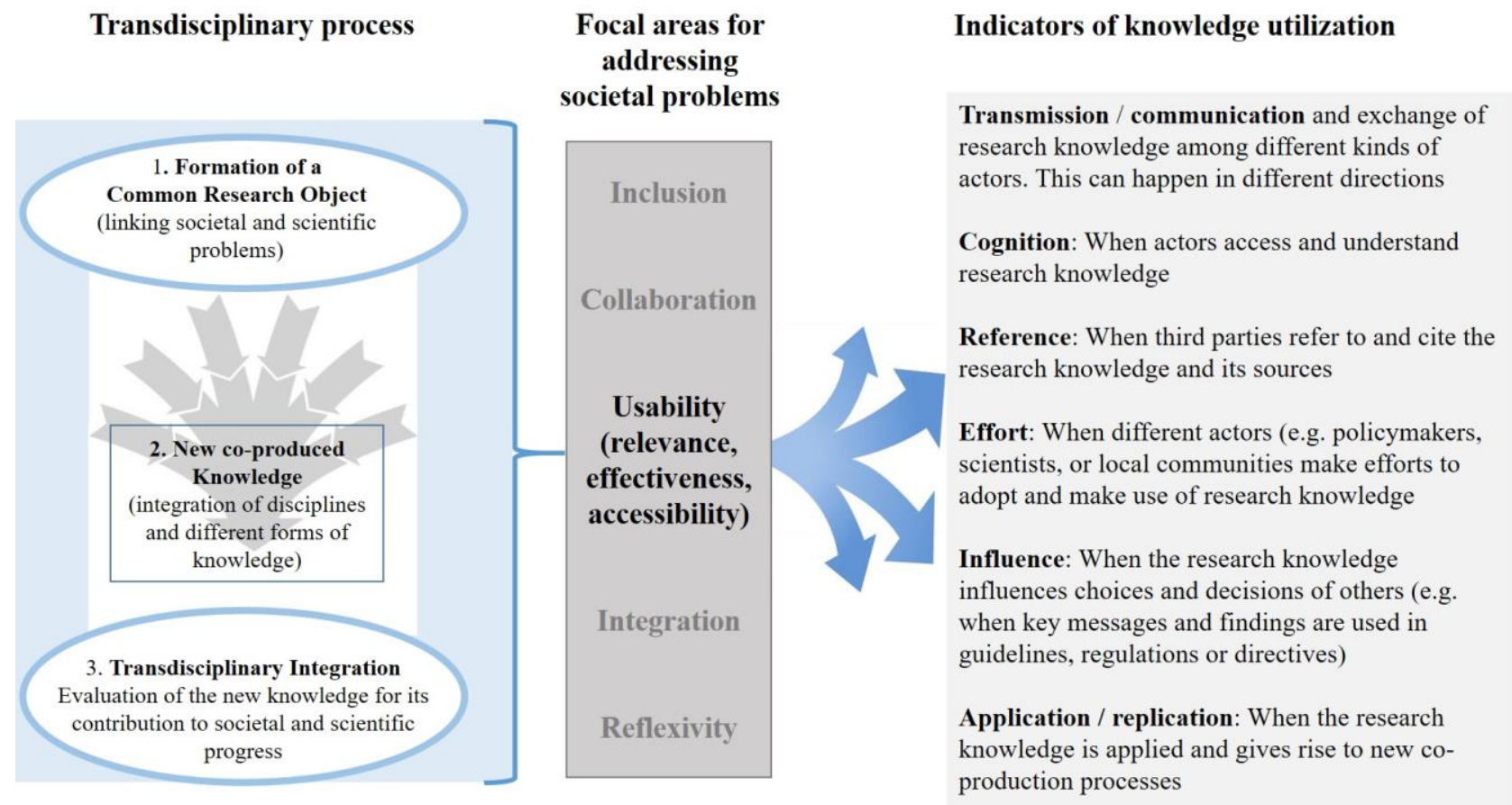

Fig. 2. Analytical framework used in this study combining a transdisciplinary process (based on Jahn et al., 2012) with focal areas (based on Polk, 2015), and indicators ("stages") of knowledge utilization (based on Landry et al., 2001).

Polk (2015) proposes five focal areas for addressing the scientific and societal problems with transdisciplinary research: inclusion, collaboration, usability, integration and reflexivity. Usability focuses on the relevance, the effectiveness and the accessibility of research knowledge for participants and other user groups, with the reflection on usability by the different actors occurring throughout the process. As co-created knowledge is a key output of transdisciplinary research (Hirsch Hadorn et al., 2006; Mobjörk, 2010; Pohl, 2008), understanding the extent to which this knowledge is later used or leads to new processes of knowledge coproduction appears to be a meaningful way getting an initial glimpse on direct and indirect project impacts or transformation.

To answer the first part of our question - i.e. if and how research knowledge from the r4d projects is being utilized - we adapt six stages of knowledge utilization proposed by Landry et al (2001): transmission, cognition, reference, effort, influence and application (Fig. 2, right side). Although initially proposed as a "ladder", we use the stages as a non-linear set of indicators due to the possible that, depending on the context conditions, several stages can occur simultaneously. In addition, the concept of unidirectional "transmission" seems at odds with knowledge co-production processes in transdisciplinary research. For example, Rist et al. (2006) show that beyond transmission, a common goal and meaning added to the knowledge through a social learning process need to be developed for the co-created knowledge to be used. However, acknowledging that 
"transmission" of knowledge happens in different forms in and from research projects, we conceptualize the process of transmission as "communication and exchange of research knowledge" happening in different directions and among all kinds of actors, and beyond the transdisciplinary research consortia.

As we built up an inductive process, we did not limit the question to a specific definition of knowledge, but kept the analysis open for any type of knowledge co-created during the transdisciplinary research projects. Not all co-created knowledge needs to be characterised as "scientific" (Keil 2012). However, as all co-created knowledge can be used in social transformation we did not limit the analysis to co-created "scientific" knowledge.

In order to achieve more nuanced insights into possible impact pathways, we additionally differentiate between three potential areas of utilization and five possible scales. The potential areas of utilization were defined according to the objectives of the programme under study: design or improvement of scientific methods or tools, generation of scientific insights, and policymaking. With regard to scale, Sheppard (2002) and Rangan and Kull (2009) have described the socio-political construction and the dynamic interaction of local and global scales in a spatial continuum. For practical reasons related to the projects design, we differentiated between five geographical scales (local, subnational, national, regional and global), and asked respondents to describe the role of scale and how it was used in the project.

We further wanted to assess possible connections of mechanisms that the projects use to other focal areas (e.g. inclusion or collaboration) to see if they enhance knowledge utilization. Therefore, we complemented the analysis of stages of knowledge utilization as indicators of impact pathways with an assessment of the perceived usefulness of eight mechanisms for promoting knowledge utilization, identified through a portfolio analysis of all project proposals included in the $\mathrm{r} 4 \mathrm{~d}$ programme (personal contact/training with key agents of change; co-creation of knowledge with key stakeholders; training of key stakeholders; publishing in scientific journals; presentations at conferences; non-scientific publications - e.g. policy briefs or reports - ; exchange platforms created by the projects; and other exchange platforms.

\subsection{Data collection and methods of analysis}

Data collection was organised in two steps; first a survey (quantitative data) asking to characterize stages of utilization of knowledge and second semi-structured interviews providing qualitative information on knowledge co-creation. At the moment of our research the $\mathrm{r} 4 \mathrm{~d}$ Programme had 46 ongoing projects. The online survey was administered to all and we obtained responses from 22 projects (one from each project). This represents $63 \%$ of the projects active within the r $4 \mathrm{~d}$ programme at the time of the survey, and $86 \%$ of the total programme funds. Nineteen projects ( $86 \%$ of the sample) included two phases of three years each, and were between middle of phase and starting phase two. The other three projects had only one three-year phase and were nearing completion. Using ongoing projects allowed us to identify utilization of co-created knowledge from the moment when integration starts to take place, thus linking utilization of research knowledge to the transdisciplinary research process as proposed by Jahn et al (2012). However, given that projects were still ongoing, our results must be understood as indicative of emerging impact pathways. Respondents were principal investigators, project coordinators, or postdocs heavily involved in the given project.

In the survey, we asked to characterize any utilization of knowledge produced in the project sphere (see Fig. 1) according to the three areas - design or improvement of scientific methods of tools, generation of scientific 
insights, and policymaking, the six stages of utilization (of which we provided definitions) and across five scales. We also asked if utilisation has been documented. Additionally, we asked respondents about the experienced usefulness of mechanisms for promoting knowledge utilization mentioned in 2.1. The survey enabled us to identify commonalities and differences regarding what co-created knowledge (areas) is being used at which utilization stages at which scales, and to elicit the respondents' perceptions regarding the usefulness of different impact mechanisms. We analysed the responses using descriptive statistics.

In order to improve understanding regarding links to the survey results and other focal areas as described by Polk (2015), we conducted semi-structured written interviews with senior researchers and project coordinators of the projects that responded to the survey. We received a total of 15 answers from all six modules (see Table $\mathrm{S} 1$ for a list of the participating projects). We asked respondents to provide in-depth information about utilization of knowledge from the project by different stakeholders and - if applicable - at multiple scales. The interviews were organized into three parts: The first concerned the mechanisms that facilitate knowledge utilization, particularly co-creation of knowledge with key stakeholders The second part focused on concrete examples of knowledge utilization at different scales including an explanation about the challenges faced. The third part was devoted to knowledge utilization in different areas; we asked to what extent the knowledge was being utilized, and what prospects the respondent saw for its future utilization. We analysed the interviews using qualitative content analysis (Mayring, 2007; Kaefer et al., 2015), and coded and analysed the interviews using Nvivo 12 Pro software. Quotes are kept anonymous in order to avoid the association of impact with specific modules or research topics, as the sample was not designed to represent those categories.

\section{Utilization of knowledge produced in a North-South research programme}

\subsection{Survey results}

The findings of the survey across all modules indicate that most projects have produced either new or improved scientific methods and tools (82\%) and/or brought new insights to science (68\%), although documentation is still relatively low to medium ( $40 \%$ and $53 \%$ of the projects, respectively). Utilization of knowledge from the projects is more frequent along all stages for new scientific methods and tools than for bringing insights to science. When it comes to bringing insights to science, utilization is highest at the stages of transmission, cognition, and reference. In both cases, the most relevant scales are national and global (Fig. 3). 


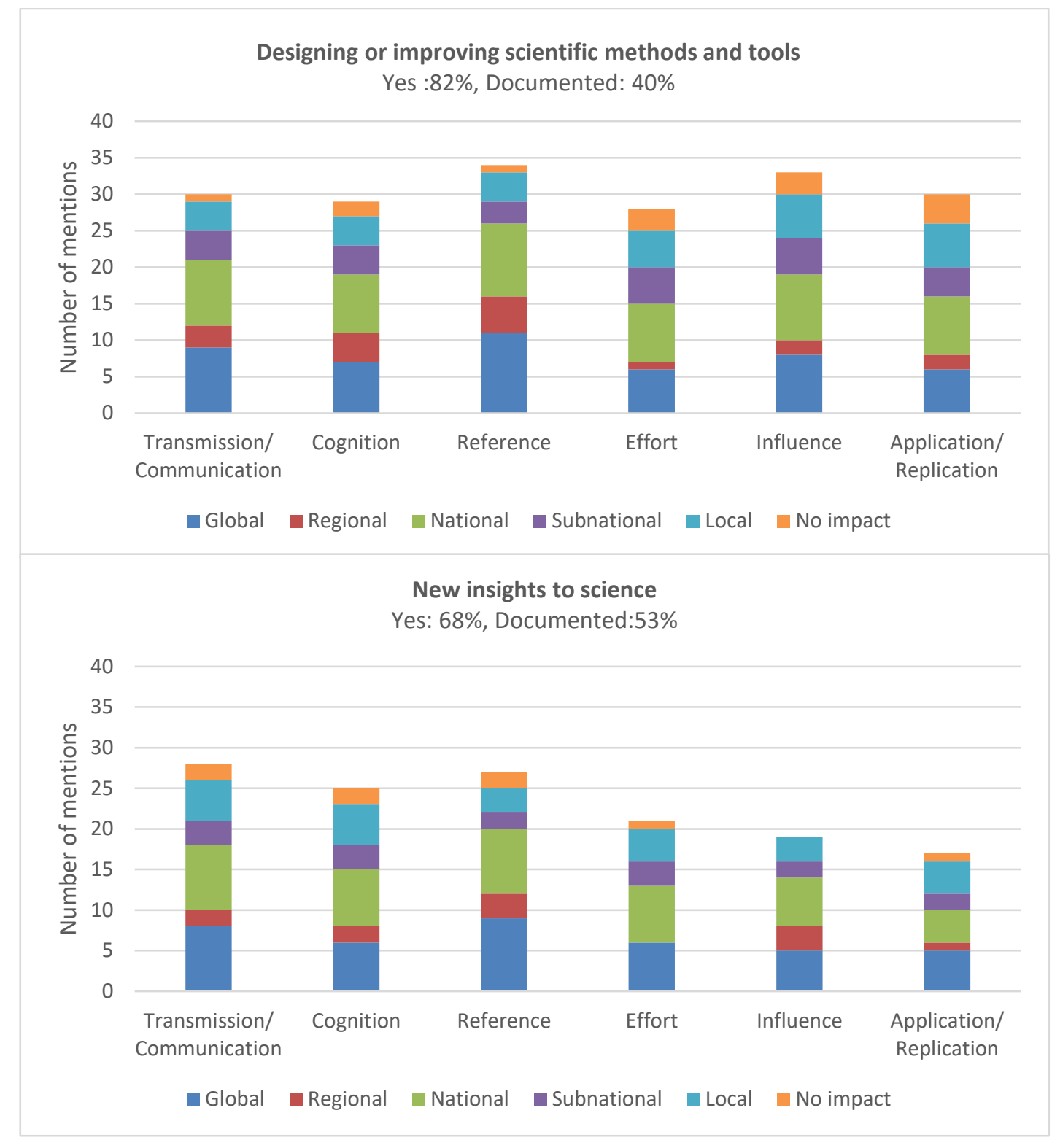

Fig. 3. Utilization of knowledge from projects in the $\mathrm{r} 4 \mathrm{~d}$ programme regarding scientific methods and tools, and new insights to science. As each project can have multiple levels of utilization at multiple scales (e.g., when thinking of a continuum, or a network), the total number of mentions per stage can be higher than the number of projects included in the survey.

Over two thirds of the projects reported utilization of knowledge from the projects in policymaking (68\%), although these effects have only been documented in publications or reports in $27 \%$ of the cases (see Fig. 4). The knowledge has been utilized in policy discussions or agreements, mainly at the national and subnational levels; transmission/communication, cognition, and effort were the most frequently reported stages. 


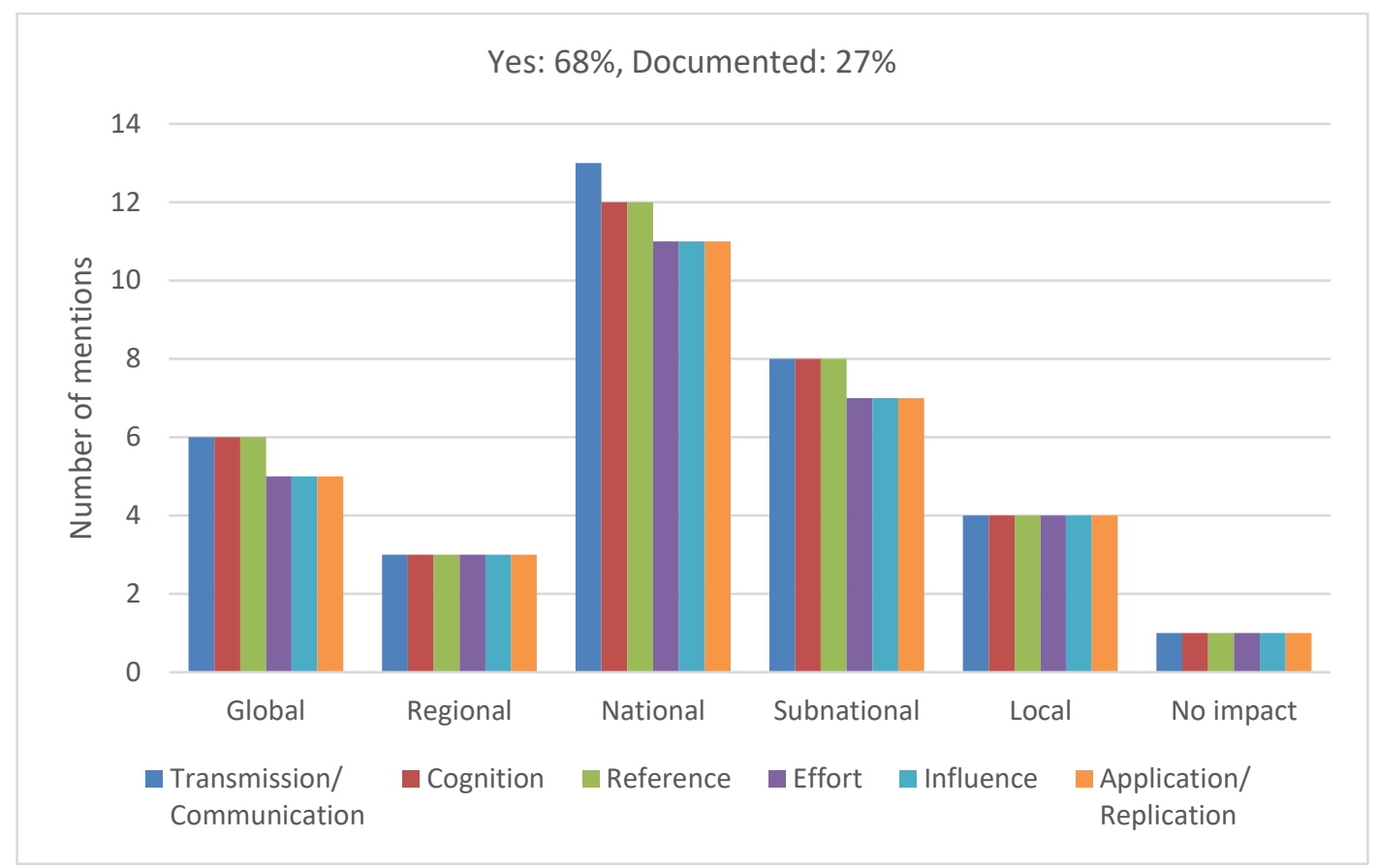

Fig. 4. Utilization of research knowledge from 22 research-for-development projects in policymaking.

The most useful mechanism to increase utilization was the co-creation of knowledge with key stakeholders, mentioned by $63.6 \%$ of respondents (Fig. 5). Exchange platforms and presentations at conferences were considered the least useful mechanisms to promote the utilization of research knowledge.

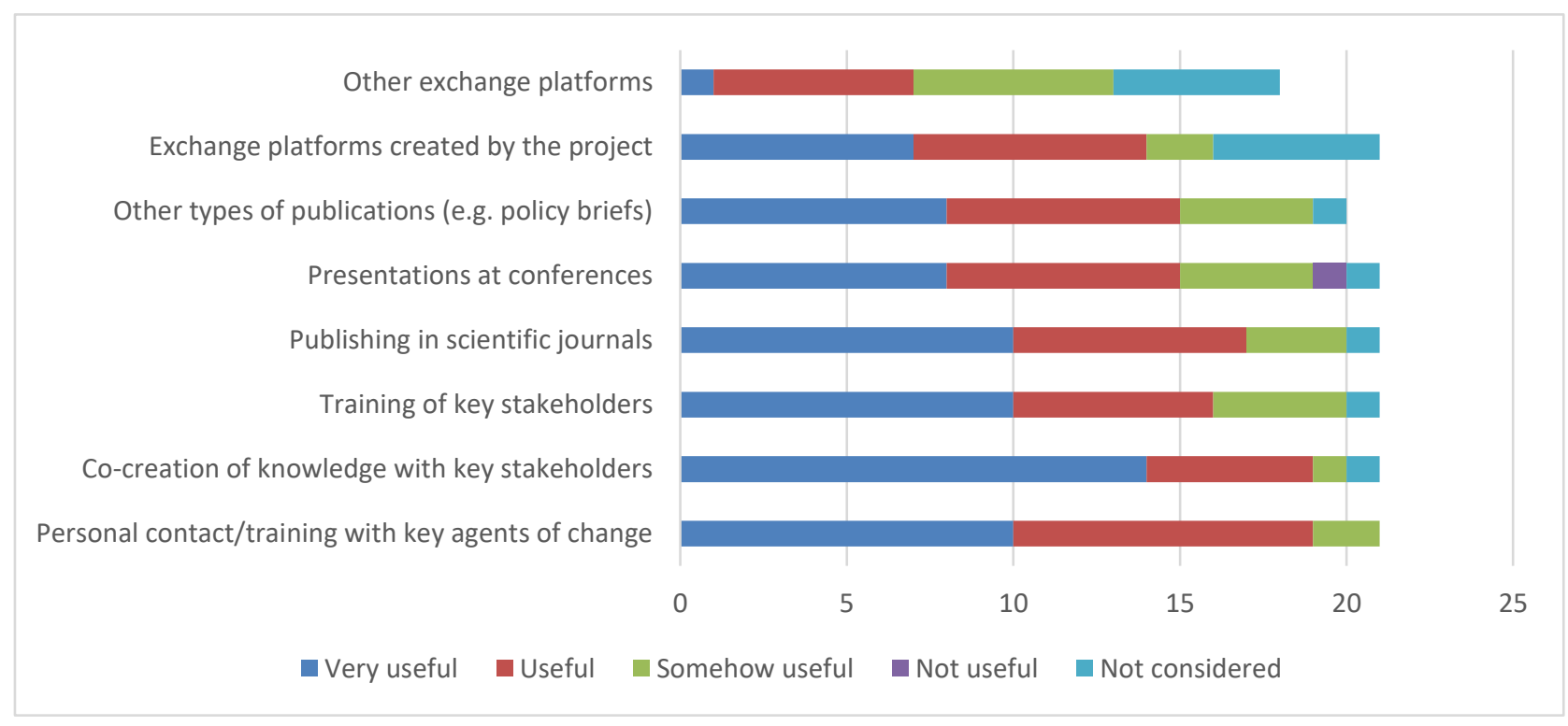

Fig. 5. Usefulness of mechanisms for promoting the utilization of knowledge as perceived by r $4 \mathrm{~d}$ researchers.

\subsection{Interview results}

In the semi-structured interviews respondents described and discussed processes of knowledge co-creation. Although the projects differ widely in terms of thematic modules (and thus disciplines) and research questions, they all had in common that they covered different scales and areas of influence and that they include partnerships with academic and non-academic organisations. The results of the survey show that the 
respondents had so far experienced "transmission / communication" and "cognition" of project knowledge, the first two stages in Landry's framework. References to the other stages were less frequent, with "reference", "effort", and "application / replication" mentioned least. Interviewees also reflected on what knowledge cocreation actually means, and described how they used this mechanism. All respondents stated that, to some extent, they used co-creation of knowledge and indicated that this mechanism offers participating actors the possibility to go beyond mere knowledge transmission / communication. In addition, comparative analysis of the responses reveals that the projects used different forms of knowledge co-creation, ranging from close everyday collaboration to dynamic interactive exchange at specific, less regular intervals. We coded this information as "understandings of co-creation" and, proceeding inductively, identified the following types: (1) obtaining information from new stakeholders (all projects); (2) providing capacity building for further use of knowledge (most projects); (3) communicating evidence in a targeted manner (all projects); (4) creating spaces for exchange and dialogue (all projects); and (5) collaborating and jointly making decisions in various phases of the project (about half of the projects). Five out of the 15 projects for which we received responses used knowledge co-creation from the project design onwards: they reported having defined the research problem or negotiated project contents jointly with different stakeholders. The remaining 10 projects started using co-creation after project funding had been secured. Thus, only a reduced number of projects fully undertook "formation of a common research object", which represents the first phase of a transdisciplinary process as expressed by Jahn et al. (2012) (Fig. 2). In terms of formats for knowledge co-creation, respondents mentioned "inclusion" or "interaction with stakeholders" (mainly workshops), "public forums", "roundtables", "everyday collaboration", "participatory mapping", and "co-authored publications". Several respondents highlighted their understanding of the role of "stakeholders". One stated that "we consider project participants also stakeholders, but not with knowledge that is superior," pointing to a perspective that considers different realities as equally justified (Max-Neef, 2005; Schneider et al., 2019). Two projects mentioned the importance of "champions" - knowledgeable individuals who need to be identified and empowered to ensure uptake and continuity. These results show a preliminary link to the focal area of inclusion as described by Polk (2015).

Further, we asked in which areas project knowledge was utilized. Seven interviewees reported that the project had had an effect on scientific methods and tools; interestingly, this was often mentioned in combination with local application (e.g. in a project on ecosystem services and social-ecological resilience in locally managed forest landscapes in Vietnam). Several projects reported that they had first had a local influence, which was later scaled up into national and sometimes even global policies (e.g. UNREDD in the case of a project active in Vietnam, or more restrictive policies on pesticides in the case of a project on food system sustainability).

Answers regarding scale were more complex. The most frequent scale reported for knowledge utilization in the survey was the national (see Fig. 4 and 6). During the interviews, this result became more nuanced: While all respondents mentioned feedback into national policies, a smaller number reported that they were working on global topics at a local scale. Apart from six projects focusing predominantly on one scale (four on the national and two on the local), five described that they had first achieved an effect at the local level, which they had then scaled up to the national level. Fewer projects first took a global approach and then translated it into local project influence. Scales were thus rather stepless or continuous than separable from each other. We identified local to global, local to national and national to local as the main vectors. Scale was connected to project duration: More advanced projects were working at more scales and continuums. Respondents' answers regarding project expectations likewise indicated that scale coverage increases with project duration. 


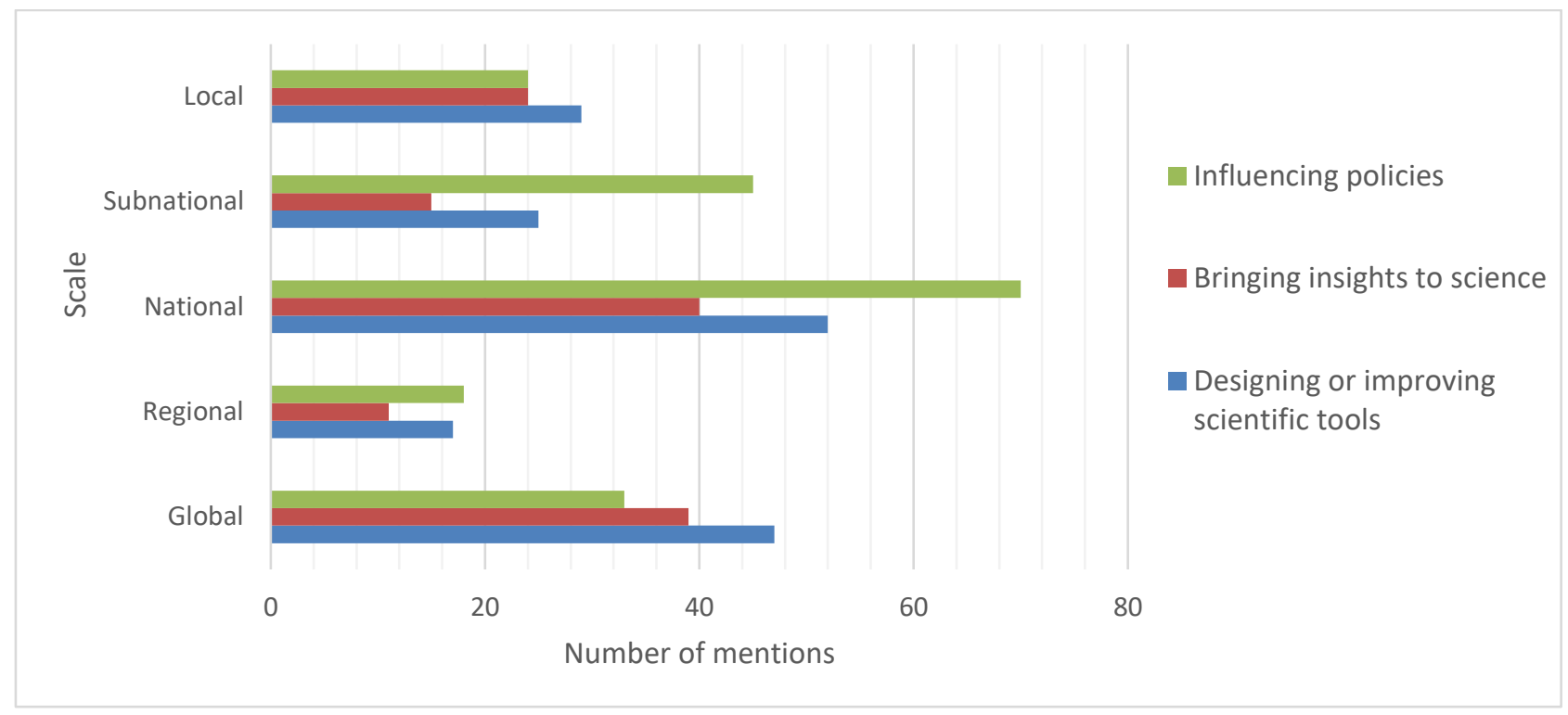

Fig. 6. Level of utilization of research knowledge per area.

Bringing together very different actors who would not otherwise have been in contact was mentioned by several respondents as an additional benefit from the co-creation process, making a link to inclusion and collaboration. For instance, one interviewee described the importance of a "very special" trust relationship between women villagers and women researchers; another described how conflicting ethnic groups were able through the project to work together and co-create knowledge. Yet another respondent from a project on land use change in Southeast Asia mentioned empowerment, friendship, and even "healing moments" in conflict situations as key benefits of knowledge co-creation, and stated that the focus on knowledge utilization is too narrow to characterize a transdisciplinary project's impact and influence on society. For example, influence on practice may concern worldviews and values, as the following quote illustrates:

"The project is not application-oriented. It's a lot about understanding better, having a more holistic perspective, etc., but what we create is not something that can be applied."

The following quote is emblematic for what several project interviews, because it exemplifies the importance given by researchers (academics and non-academics) to inclusion and collaboration for facilitating not only usability but also transformation:

"There might be some influences on practices, but more the deeper things (e.g. mindsets, worldviews, and values). This refers to the leverage points discussion: Normally, we just focus on the more obvious leverage points and not so much on the deep ones. On the level of these deeper things (mindsets etc.), we can maybe say that something is happening through our project, not the concrete changes in practice like introducing a new crop, but these deeper changes."

In terms of factors enabling the utilization of research knowledge, three projects mentioned early involvement of key stakeholders in the project (belonging to inclusion, see Fig. 2); two mentioned communication in local languages through local media. Similarly, early involvement of knowledge users was mentioned as conducive to subsequent utilization of the knowledge. The most frequently mentioned enabling factor, however, was equal empowerment of stakeholders. According to one project team, true " co-creation' can only happen when all people involved are given the same power to steer the process." 
Respondents also mentioned a range of challenges. A majority of the interviewees reported third-party interest in their results, for instance from policymakers who asked to receive the research results in a form understandable to non-scientific actors, often at national or regional scales. Nevertheless, lack of political will was mentioned in seven interviews as a barrier to utilization, especially when research results were inconvenient or challenged current political agendas. As stated by an interviewee, if the project results

“...question what has been advocated by influential actors", politicians tend to stick to their previous position in public - even though they may appear convinced when research results are transferred. Several respondents mentioned that time and resource constraints prevented them from disseminating the generated knowledge more effectively. Some mentioned that building networks takes time and is difficult, and that a lack of networks can hamper co-creation processes and uptake of research knowledge. Lastly, researchers' communication skills, as well as strategies for transmitting results (reportedly often requested by other stakeholders), were regarded as a challenge for the utilization of research knowledge outside the projects. The complexity of the social-ecological systems and the multidimensionality of the problems investigated makes it even more difficult to communicate results in a tangible way; moreover, several researchers stated that they do not like to simplify complex issues for communicative purposes.

One respondent summarized monitoring difficulties in transdisciplinary projects as follows, indicating that quantification of project impacts may fail to capture the added value of transdisciplinary work:

"Given that monitoring social change in time and space is extremely difficult, the quantification of transdisciplinary research impacts is a challenge. While top-down initiatives (e.g. new policies) are easy to document, monitoring bottom-up changes is too costly and there is a risk of over-monitoring that may affect the social process under examination."

Regarding expected project impacts in the long term, the more temporally advanced projects were, the more concrete were their expectations, and the fewer areas and scales respondents named. However, almost all had expectations regarding utilization of project knowledge in policymaking. Further impact on science was less frequently mentioned, but was implicitly present in the interviews through mentions of scientific publications, conferences, and educational activities. Although practical application was mentioned least (by only four projects), respondents used terms such as "hope" and "long-term effects" regarding all areas. One example was the following quote: "We believe that we can influence decision-makers at the micro-level (local) and thereby pursue a bottom-up approach (...) The research outcomes will be used for the policymaking process as well as for improving the quality of forest management mechanisms (...) also in other countries which share similar contexts."

\section{Towards understanding impact}

Knowledge from the analysed projects was utilized in multiple areas and at multiple stages simultaneously: For instance, projects developed scientific tools and methods while facilitating a policy dialogue and cocreation with multiple social agents. Our research shows that the stages of knowledge utilization proposed by Landry et al (2001), if integrated into a broader framework and adapted to transdisciplinary research processes, are one possibility to characterize usability as a proxy for assessing impact pathways from transdisciplinary projects. An exclusively linear understanding of knowledge utilization is inadequate, because it does not correspond to the complexity of the systems under research, nor to the diversity of development pathways that 
a research project can use when taking inclusive and participative approaches. This finding provides further evidence regarding the multiplicity of possible impact pathways of research-for-development activities that transdisciplinary approaches take (Manners and van Etten, 2018; Jagustović et al., 2019).

While almost all projects were able to document their contributions to scientific methods and tools, utilization of co-created knowledge in other areas was far less documented. However, many respondents reported requests from policymakers and other actors to prepare their results in an accessible way to enable utilization. The interviews indicated that the co-created knowledge always has components referring to different scales even if the process of co-creation is local. The continuous scales used in most of the project might therefore be best described as "glocal" (e.g. Haller et al. 2019). Respondents also indicated that project influence grows gradually and can therefore not be restricted to one project nor documented only during or shortly after its lifetime.

There are multiple possible explanations for the time it takes for impacts of scientific knowledge co-creation to unfold. For instance, Haller et al. (2015) describe the importance of local agency in institution building despite power asymmetries, and highlight the prevailing top-down nature of many development activities that do not enhance communicative action from local levels. Indeed, power relations are one of the most determining issues in transdisciplinary science (Rosendahl et al. 2015; Schmidt and Pröpper, 2018). The topic of top-down and bottom-up approaches was discussed in two interviews, indicating that top-down impacts are often easier to document and more visible in the short term, and therefore possibly more strongly pursued in projects whose performance is monitored using conventional criteria (Basche et al., 2014; Burkhardt-Holm and Zehnder, 2018; Hansson and Polk, 2018). Overall, the interviews highlighted that an outcome-oriented focus may be too narrow to understand the impacts of transdisciplinary research-for-development projects. The evaluation of such projects requires value- and process-oriented frameworks like the one described in Schneider et al. (2019) rather than a linear project management logic. This poses an interesting challenge in defining the right moment in time for promoting synthesis or evaluation activities that help to maximize impact by contextualizing and integrating research findings and procedural learnings beyond individual projects. If such work is done during the lifetime of the projects, they can profit from insights beyond their own research. However, during the lifetime of the projects it is not possible to appreciate the whole range of impacts, which is often a major interest of donors and, to a lesser extent, of policymakers in donors' countries.

With regard to mechanisms for promoting knowledge utilization, most survey respondents and all interviewees identified knowledge co-creation as the preferred one. More concretely, the interviews highlighted the importance of inclusion and collaboration as key to enhancing usability of the research knowledge. This may partly be predetermined by the basic characteristics of the $\mathrm{r} 4 \mathrm{~d}$ programme, which funds projects that declaredly aim to facilitate the utilization of inter- and transdisciplinary research results in policy and practice (Eidgenossisches Departement für auswärtige Angelegenheiten et al., 2014) and cannot be generalized to all transdisciplinary research projects.

Understandings of knowledge co-creation in the interviews seem to range widely, from joint project design which may include all five focal areas described by Polk (2015)- to co-authored scientific publications - not necessarily in line with these focal areas. If we relate the differing understandings of co-creation to the four categories established by Krütli et al. (2010) - information, consultation, collaboration and empowerment which may indicate the "strength" of the transdisciplinary approach, all projects in our study have overcome the phase of mere "information", and most projects seem somewhere between "consultation" and 
"collaboration". Several interviewees mentioned the importance of "empowerment" in terms of creating opportunities for different actors to decide which type of knowledge they want to use. Also, empowerment was mentioned as an important consequence of promoting the utilization of research knowledge in different areas and at different scales. This may be an important point for consideration in further transdisciplinary research in north-south context. In this line, Chilisa (2017) shows how non-western knowledge systems are still being marginalized in transdisciplinary research, because of a prevailing dominance of European or western paradigms and methods. Such an exclusion often leads to interventions that are not compatible with local populations and represent a barrier to application / replication. Indigenous groups and their epistemologies must therefore be empowered in the transdisciplinary process (Chilisa, 2017). Interviewees in our research cases described two types of empowerment: (1) empowerment of groups - for instance a group of marginalized actors such as small-scale farmers - to give them a voice; and (2) empowerment of individuals, which some respondents named "champions" or "agents of change". In addition, respondents highlighted the need to be aware that additional time and competences are necessary to secure the empowerment of groups or change agents, otherwise the outcomes tend to become too uncertain. We agree with other authors on the importance of empowerment as a key feature of transdisciplinary research, because its relation to legitimacy and transformation processes (Brandt et al., 2013; Popa et al., 2015). However, our results can only been considered as indicative in this regard, as the evidence base is small.

We recognize the existence of some conceptual guidance about potential strategies for empowerment, including co-design or joint development of project goals and concepts (see Pohl et al. 2010). Researchers (e.g., Schneider et al., 2019) have highlighted that transdisciplinary approaches should not consist simply of improved communication or increased consultation, but should imply that knowledge is produced in an equitable way. In a similar sense, Max-Neef (2005) introduced the concepts of "strong" and "weak" transdisciplinarity, where "strong" transdisciplinarity includes the epistemological challenge of embracing different realities, understandings, and perspectives, while "weak" transdisciplinarity is more aligned with the pre-existing views of a specific stakeholder group and/or does not challenge traditional methods and logic. However, our study shows that there is a need to improve understanding of the extent of empowerment achieved through transdisciplinary approaches as well as the means and resources required for securing it. Some testimonies pointed out the challenges faced when new actors are included (inclusion and collaboration) and empowered through transdisciplinary approaches, or when research results are not aligned with existing policies and predominant narratives. These testimonies are in line with other scientists' conclusions regarding the epistemological challenge inherent in strong transdisciplinarity, which, for instance, involves questioning existing power relations and the idea of "scientific neutrality" (Rosendahl et al., 2015). In order to produce reliable and "socially robust" knowledge and promote transformation towards sustainable development, transdisciplinary research-for-development projects must be inclusive, relevant, credible, and legitimate (Hansson and Polk 2018). This implies that researchers and research programme designers need to be capable of reflecting the diversity, complexity, and dynamic nature of the complex systems under consideration. To achieve this, actors using transdisciplinary approaches will need the time and competences it takes to secure mutual learning and dialogue between scientific and non-scientific stakeholders coming from different cultures and using a potentially different value system (see Hirsch Hadorn et al., 2006). Thus, contextualized knowledge is needed in order to identify both potential risks and existing opportunities related to empowerment processes in the areas where research for development takes place. 


\section{Conclusions and outlook}

Using an adapted framework of stages of utilization of research knowledge at various impact areas from local to global, we analysed how research-for-development projects co-create knowledge and how this knowledge is utilized in science and policymaking. We found that research knowledge from projects in the r4d programme is being utilized at multiple stages simultaneously, reflecting diverse and non-linear patterns of knowledge utilization at continuous scales and in different areas at the same time -i.e. to improve scientific methods and tools, to generate new scientific insights, and in policymaking. Application in practices was also reported from several projects. Thus, the results of this study can be understood as an approximation to understanding transformation pathways using transdisciplinary research knowledge.

We also looked at the mechanisms employed to facilitate knowledge utilization. "Co-creation" of knowledge was selected as the most frequent mechanism. Information from supplementary interviews led us to conclude that, although different understandings of "co-creation" coexist in the $\mathrm{r} 4 \mathrm{~d}$ programme, the mechanism allows to increase inclusion and collaboration thus facilitating usability and promoting empowerment of new actors. This is in line with the ongoing discussion about transdisciplinary research and knowledge co-creation being a means to empower social groups otherwise marginalized, so that they can help shape deliberation processes aimed at sustainable development. This suggests that "empowerment" could be used as an additional proxy for understanding impact pathways of this type of research. Such a normative approach would involve assessing the deliberative opportunities that projects offer stakeholders, for example regarding decisions on budget allocation, project contents, and project goals.

Two limitations to our study require clarification. First, while the fact that all projects in our study belong to the same research programme ensures a certain level of comparability between projects, it also introduces an internal bias, as all projects contribute to a limited, predefined set of goals and fulfil the same selection criteria. For this reason, the results should be generalized with caution. The second limitation relates to a possible wide variety of understandings among study participants of several key concepts, including the stages of knowledge utilization. Although we used a predefined set of definitions, respondents' individual interpretations may have influenced the answers.

Transformations towards sustainable development require behavioural and structural changes alike. Transdisciplinary research as it is pursued by the $\mathrm{r} 4 \mathrm{~d}$ programme can contribute to understanding and advancing the necessary changes based on its multi-stakeholder approach, knowledge co-creation, and possibly empowerment of otherwise marginalized actors. These characteristics of transdisciplinary research certainly increase the utilization of research knowledge along multiple impact pathways. However, variation in the questionnaire responses and the more differentiated views expressed in the interviews indicate a need for better understanding the contextual requirements for knowledge co-creation.

\section{Acknowledgements}

The Swiss Programme for Research on Global Issues for Development ( $\mathrm{r} 4 \mathrm{~d}$ programme) funded all projects included in this study, as well as the development of the analytical framework. The latter is included in one of the r $4 \mathrm{~d}$ programme's synthesis streams. The $\mathrm{r} 4 \mathrm{~d}$ programme is a joint funding initiative by the Swiss Agency for Development and Cooperation (SDC) and the Swiss National Science Foundation (SNSF). The authors gratefully acknowledge the information provided by those $\mathrm{r} 4 \mathrm{~d}$ researchers that either filled in the 
survey and/or participated in the interviews. R. Eschen and M Kenis were supported by CABI with core financial support from its member countries (see http://www.cabi.org/about-cabi/who-we-work-with/keydonors/).

\section{References}

Archibald, T., Sharrock, G., Buckley, J., Cook, N., 2016. Assumptions, conjectures, and other miracles: The application of evaluative thinking to theory of change models in community development. Eval. Program Plann. 59, 119-127. https://doi.org/10.1016/j.evalprogplan.2016.05.015

Basche, A.D., Roesch-McNally, G.E., Pease, L.A., Eidson, C.D., Lahdou, G.B., Dunbar, M.W., Frank, T.J., Frescoln, L., Gu, L., Nagelkirk, R., Pantoja, J., Wilke, A.K., 2014. Challenges and opportunities in transdisciplinary science: The experience of next generation scientists in an agriculture and climate research collaboration. J. Soil Water Conserv. 69, 176A-179A. https://doi.org/10.2489/jswc.69.6.176A

Belcher, B., Palenberg, M., 2018. Outcomes and Impacts of Development Interventions: Toward Conceptual Clarity. Am. J. Eval. 1098214018765698. https://doi.org/10.1177/1098214018765698

Brandt, P., Ernst, A., Gralla, F., Luederitz, C., Lang, D.J., Newig, J., Reinert, F., Abson, D.J., von Wehrden, H., 2013. A review of transdisciplinary research in sustainability science. Land Use 92, 1-15. https://doi.org/10.1016/j.ecolecon.2013.04.008

Bunders, J.F.G., Broerse, J.E.W., Keil, F., Pohl, C., Scholz, R.W., Zweekhorst, M.B.M., 2010. How can transdisciplinary research contribute to knowledge democracy?, in: in 't Veld, R.J. (Ed.), Knowledge Democracy: Consequences for Science, Politics, and Media. Springer Berlin Heidelberg, Berlin, Heidelberg, pp. 125-152. https://doi.org/10.1007/978-3-642-11381-9_11

Burkhardt-Holm, P., Zehnder, A.J.B., 2018. Fischnetz: Assessing outcomes and impacts of a project at the interface of science and public policy. Environ. Sci. Policy 82, 52-59. https://doi.org/10.1016/j.envsci.2018.01.010

Chilisa, B., 2017. Decolonising transdisciplinary research approaches: An African perspective for enhancing knowledge integration in sustainability science. Sustainability Science, 12 (5), 813-827. https://doi.org/10.1007/s11625-017-0461-1

Eidgenossisches Departement für auswärtige Angelegenheiten, Direktion für Entwicklungszusammenarbeit DEZA, Schweizerischer Nationalfonds zur Förderung der wissenschaftlichen Forschung, 2014. Swiss Programme for Research on Global Issues for Development (r4d.ch). Detailkonzept.

ESRC, 2011. 'Branching Out. New Directions in Impact Evaluation from the ESRC's Evaluation Committee'. http://www.esrc.ac.uk/research/research-and-impact-evaluation/analysis-andscoping/ last access 12th of January 2017.

Haller, T., Acciaioli, G., Rist, S., 2015. Constitutionality: Conditions for Crafting Local Ownership of Instituion-Building Processes. Sciety \& Natural Resources: An International Journal, DOI: 10.1080/08941920.2015.1041661

Hansson, S., Polk, M., 2018. Assessing the impact of transdisciplinary research: The usefulness of relevance, credibility, and legitimacy for understanding the link between process and impact. Res. Eval. 27, 132144. https://doi.org/10.1093/reseval/rvy004

Hirsch Hadorn, G., Bradley, D., Pohl, C., Rist, S., Wiesmann, U., 2006. Implications of transdisciplinarity for sustainability research. Ecol. Econ. 60, 119-128. https://doi.org/10.1016/j.ecolecon.2005.12.002

Jahn, T., Bergmann, M., Keil, F., 2012. Transdisciplinarity: Between mainstreaming and marginalization. Ecological Economics, 79, 1-10. https://doi.org/10.1016/j.ecolecon.2012.04.017 
Krütli, P., Stauffacher, M., Flüeler, T., Scholz, R.W. 2010. Functional-dynamic public participation in technological decision-making: Site selection processes of nuclear waste repositories. Journal of Risk Research 13(7): 861-875

Landry, R., Amara, N., Lamari, M., 2001. Climbing the Ladder of Research Utilization: Evidence from Social Science Research. Sci. Commun. 22, 396-422. https://doi.org/10.1177/1075547001022004003

Levesque, V.R., Calhoun, A.J.K., Bell, K.P., 2019. Actions speak louder than words: designing transdisciplinary approaches to enact solutions. J. Environ. Stud. Sci. 9, 159-169. https://doi.org/10.1007/s13412-018-0535-0

Max-Neef, M. A., 2005. Foundations of transdisciplinarity. Ecological Economics 53, 5-16, doi:10.1016/j.ecolecon.2005.01.014

Mayring, P. (2007): Qualitative Inhaltsanalyse: Beltz UTB., 9. Auflage, Weinheim.

Miller, T.R., Wiek, A., Sarewitz, D., Robinson, J., Olsson, L., Kriebel, D., Loorbach, D., 2014. The future of sustainability science: a solutions-oriented research agenda. Sustain. Sci. 9, 239-246. https://doi.org/10.1007/s11625-013-0224-6

Mobjörk, M., 2010. Consulting versus participatory transdisciplinarity: A refined classification of transdisciplinary research. Futures, Europe 2030: Territorial Scenarios 42, 866-873. https://doi.org/10.1016/j.futures.2010.03.003

Nutley, S. M., Walter, I., Davies, H. T. O., 2007. 'Using Evidence: How Research Can Inform Public Services. Bristol University Press.

Palenberg, M., 2011. Tools and Methods for Evaluating the Efficiency of Development Interventions, Evaluation Working Papers. Federal Ministry of Economic Cooperation and Development of Germany, Bonn, Germany.

Pohl, C., 2008. From science to policy through transdisciplinary research. Environ. Sci. Policy 11, 46-53. https://doi.org/10.1016/j.envsci.2007.06.001

Pohl, C., Krütli, P., Stauffacher, M., 2017. Ten Reflective Steps for Rendering Research Societally Relevant [WWW Document]. https://doi.org/info:doi/10.14512/gaia.26.1.10

Polk, M., 2015. Transdisciplinary co-production: Designing and testing a transdisciplinary research framework for societal problem solving. Futures, "Advances in transdisciplinarity 20042014" 65, 110-122. https://doi.org/10.1016/j.futures.2014.11.001

Popa, F., Guillermin, M., Dedeurwaerdere, T. 2015. A pragmatist approach to transdisciplinarity in sustainability research: From complex systems theory to reflexive science. Futures. Advances in transdisciplinarity 2004-2014, 65 (Januar): 45-56. https://doi.org/10.1016/j.futures.2014.02.002.

Rangan, H., Kull, C. A., 2009. What makes ecology 'political'?: rethinking 'scale' in political ecology. Progress in Human Geography 33(1), 28-45. DOI: 10.1177/0309132508090215

Rosendahl, J., Zanella, M. A., Rist, S., Weigelt, J., 2015. Scientists' situated knowledge: Strong objectivity in transdisciplinarity. Futures 65, 17-27, http://dx.doi.org/10.1016/j.futures.2014.10.011

Russell, A.W., Wickson, F., Carew, A.L., 2008. Transdisciplinarity: Context, contradictions and capacity. Futures 40, 460-472. https://doi.org/10.1016/j.futures.2007.10.005

Schmidt, L., Pröpper, M., 2017. Transdisciplinarity as a real-world challenge: a case study on a North-South collaboration. Sustainability Science, 12(3), 365-379. https://doi.org/10.1007/s11625-017-0430-8

Schneider, F., Buser, T., 2018. Promising degrees of stakeholder interaction in research for sustainable development. Sustain. Sci. 13, 129-142. https://doi.org/10.1007/s11625-017-0507-4

Schneider, F., Buser, T., Keller, R., Tribaldos, T., Rist, S., 2019. Research funding programmes aiming for societal transformations: ten key stages. Sci. Public Policy. https://doi.org/10.1093/scipol/scy074

Sheppard, E., 2002. The Spaces and Times of Globalization: Place, Scale, Networks, and Positionality. Economic Geography, 78 (3), 307-330. https://doi.org/10.2307/4140812 
Spreckley, F., 2009. Result Based Monitoring and Evaluation Toolkit. Second Edition. Local Livelihoods, Herefordshire, United Kingdom.

Thompson, M.A., Owen, S., Lindsay, J.M., Leonard, G.S., Cronin, S.J., 2017. Scientist and stakeholder perspectives of transdisciplinary research: Early attitudes, expectations, and tensions. Environ. Sci. Policy 74, 30-39. https://doi.org/10.1016/j.envsci.2017.04.006

Thornton, P., Schuetz, T., Förch, W., Cramer, L., Abreu, D., Vermeulen, S., Campbell, B., 2017. Responding to global change: A theory of change approach to making agricultural research for development outcome-based. Agric. Syst. 152, 145-153. https://doi.org/10.1016/j.agsy.2017.01.005

Wiek, A., Ness, B., Schweizer-Ries, P., Brand, F.S., Farioli, F., 2012. From complex systems analysis to transformational change: a comparative appraisal of sustainability science projects. Sustain. Sci. 7, 5-24. https://doi.org/10.1007/s11625-011-0148-y

Zaehringer, J. G., Schneider, F., Heinimann, A., and Messerli, P. 2019., 'Co-Producing Knowledge for Sustainable Development in Telecoupled Land Systems'. In Telecoupling: Exploring Land-Use Change in a Globalised World, edited by Cecilie Friis and Jonas $\emptyset$. Nielsen, 357-81. Palgrave Studies in Natural Resource Management. Cham: Springer International Publishing. https://doi.org/10.1007/978-3-030-11105-2_19. 